\title{
Eosinophilic leukaemia: Morphological, cytochemical, and electron microscopic studies
}

\author{
B. PRESENTEY, Z. JERUShALMY, AND U. MINTZ ${ }^{1}$
}

From the Rogoff-Wellcome Medical Research Institute and the Department of Oncology, Beilinson Medical Center, Tel-Aviv University Medical School, and the Department of Hematology, Kupath Holim, District Laboratory, Rehovoth, Israel

SUMMARY The eosinophils of a patient with eosinophilic leukaemia were studied with 13 different cytochemical methods using light and electron microscopy. Apart from the 'left shift' of the eosinophils in bone marrow and peripheral blood, the following morphological changes were noted: uncoordinated maturation of the nucleus and cytoplasm, changes in size of the specific granules, and hypogranulation to such an extent that some of the cells bore only very few granules. The cytochemical studies showed a strongly positive periodic acid Schiff reaction in the eosinophils, caused by a high content of glycogen, and a relatively strong positive acid-phosphatase reaction. These cells were also tested for aryl sulphatase and coenzyme Q. Electron microscopy confirmed the presence of a high-content glycogen and a strong acid phosphatase response in the cells. Peroxidase reaction, detected in electron microscopy as well, enabled us to trace the maturation of the eosinophil cell line.

Although eosinophilic leukaemia has recently gained acceptance as a distinct disease entity (Gross, 1962) its diagnosis is difficult in certain cases (Zucker-Franklin, 1971) because eosinophilia may also be secondary to antigenic stimuli as well as a reaction to various underlying diseases (Bently et al., 1961; Odeberg, 1965; Karle and Videbaek, 1966; Bengtsson, 1968; Benvenisti and Ultmann, 1969; Flannery et al., 1972; Spitzer and Garson, 1973; Tallgren et al., 1974; Yuill et al., 1974; Zucker-Franklin, 1974). Hardy and Anderson (1968) and Chusid et al. (1975) have proposed that eosinophilic leukaemia is part of a spectrum of hypereosinophilic diseases called the hypereosinophilic syndrome. The rarity of this condition, however, hinders the establishment of clearcut diagnostic criteria.

Cytochemical studies of eosinophilic leukaemia are still scarce. According to Gross (1962), the disease is characterised by chromosomal aberration, a shift to the left in the bone marrow eosinophilic series, variation in the size and number of the

${ }^{1}$ Present address: Department of Medicine, Section of Hematology/Oncology, The University of Chicago, 950 East 59th Street, Box 420, Chicago, Illinois 60637, USA

Received for publication 26 June 1978

Amended version received 14 November 1978 specific eosinophilic granules, and the presence in the cell cytoplasm of numerous azurophilic-basophilic granules as well as of vacuoles. Additional features mentioned by Gross (1962) are accumulation of glycogen and positive reaction to naphthol AS-D chloroacetate. Ackerman (1964) observed asynchronous nuclear-cytoplasmic maturation, increase in cell size, and morphological changes in the specific granules; he also noted fibrillar formations, a large amount of glycogen, increased phosphorylase activity, and strongly positive acid phosphatase reaction in the eosinophils. Schaefer et al. (1973) detected in the eosinophils of some patients AS-D chloroacetate activity and an increased amount of polysaccharides, while Wulfhekel et al. (1975) and Weinger et al. (1975) reported a high glycogen content in eosinophils as well as some alterations detectable by electron microscopy.

In the present study we describe the results of morphological and cytochemical studies of eosinophils of a patient with eosinophilic leukaemia using both light and electron microscopy.

\section{Material and methods}

CASE PRESENTATION

A 42-year-old man had been diagnosed one year previously in another hospital as having chronic eosinophilic leukaemia. Leucocyte alkaline phospha- 
tase score was 184 (normal 15-70), the highest peripheral leucocyte count was $14 \times 10^{9} / 1$, and karyotyping did not disclose $\mathrm{Ph}^{\prime}$ chromosome. A bone marrow aspirate was highly cellular with a myeloid to erythroid ratio of $4: 1$. The myeloid series consisted of $40 \%$ eosinophils in various stages of maturation from promyelocytes to mature cells. No other abnormalities were found in the myelogram. The disease was complicated by epidural myeloblastoma causing cord compression. A case report, including the patient's serum vitamin $\mathbf{B}_{12}$ and $\mathrm{B}_{12}$-binding proteins, has already been published (Dvilansky et al., 1975). The patient was treated by surgical removal of the tumour and was then transferred to our department for irradiation of the spinal tumour bed. He was first seen by us in July 1974. On admission to our hospital hepatosplenomegaly was evident, and the neurological examination revealed paraplegia. The haemoglobin was $11.9 \mathrm{~g} / \mathrm{dl}$, the white blood cell count $6.5 \times 10^{9} / 1$, the differential count showed $25 \%$ polymorphonuclear neutrophils, $5 \%$ band forms, $20 \%$ lymphocytes, $4 \%$ monocytes, $45 \%$ eosinophils, and $1 \%$ myelocytes. The platelet count was $146 \times 10^{9} / 1$ and the serum level of vitamin $B_{12}-4160 \mu \mathrm{g} / \mathrm{ml}$. The patient died two months later, in another hospital, of septic shock.

CYTOCHEMICAL STUDIES ON PERIPHERAL BLOOD AND BONE MARROW EOSINOPHILS Eosinophils obtained from the peripheral blood and bone marrow were examined. Staining for phospholipids was performed with Sudan Black B using the method of Lison (1973) or Sheehan (1939). Polysaccharides were stained by periodic acid-Schiff reagent (PAS), before and after treatment with diastase (Hotchkiss, 1948). Basic proteins were stained by Luxol fast blue (LFB) in urea-saturated alcoholic solution (Goldstein, 1963). Combined staining for simultaneous detection of phospholipids, polysaccharides, and basic proteins was performed as previously described by Presentey and Perk (1972). The methods used for the study of enzymatic activities were those described by the following authors: peroxidase, Graham and Knoll (1973); peroxidase modified for eosinophils, Undritz (1973); alkaline phosphatase activity, Kaplow (1955); acid phosphatase, Gomori (1968); aryl sulphatase, Goldfischer (1965); ubiquinone (coenzyme Q), Tranzer and Pearse (1963); nonspecific esterases in the presence of the substrates naphthol AS-D chloroacetate (Moloney et al., 1960) or $a$-naphthyl acetate (Gomori, 1952).

ELECTRON MICROSCOPIC STUDIES

Blood drawn with 10 IU heparin per ml was kept at room temperature for 30 minutes. The buffy coat was then collected and processed as previously described by Watanabe et al. (1967). Aspirated bone marrow was processed according to the method of Ackerman and Clark (1971). For the dehydrationreaction with phosphotungstic acid (PTA) the procedure of Hudson (1966a) was applied, for the detection of peroxidase activity that of Ackerman and Clark (1971), and for acid phosphatase the method of Seeman and Palade (1967). Reaction to pyroantimonate was detected in non-glutaraldehydetreated peripheral blood, buffy coat or bone marrow cells using the method of Hardin and Spicer (1970).

Sections for electron microscopy were prepared by LKB Pyramidone and LKB microtome and placed on uncovered $300-400$ mesh grids. Slices fixed in glutaraldehyde and $\mathrm{OsO}_{4}$ without pretreatment were stained with uranyl acetate and lead citrate. No staining was performed on slices examined for enzymatic activity, or on slices treated with PTA (Hudson, 1966a) or pyroantimonate (Hardin and Spicer, 1970). The slides were examined with a JEM-7 electron microscope.

\section{Results}

\section{LIGHT MICROSCOPY}

Both bone marrow and peripheral blood contained a large number of eosinophils. In the bone marrow the majority of the promyelocytes and myelocytes were of the eosinophilic series, and numerous blasts were evident. Eosinophilic promyelocytes and myelocytes were also found in the peripheral blood, and the apparent mature eosinophils showed hypersegmentation. Both the bone marrow and peripheral blood eosinophils showed asynchrony of nuclear and cytoplasmic maturation. A significant reduction in the number of specific granules was observed in some of the eosinophils, both immature and mature; in the majority of eosinophils, however, these granules were larger or smaller than usual (Fig. 1). Many of the eosinophils (23 out of 100 in the peripheral blood) contained up to six or more cytoplasmic vacuoles (Fig. 2).

\section{CYTOCHEMISTRY}

The specific granules of the eosinophils contained basic proteins whereas phospholipids were detected in both the granules of the eosinophils and those of the neutrophilic polymorphonuclears. Polysaccharides, sometimes in large masses, were found in the cytoplasm of the cells (Fig. 3). After pretreatment with diastase, the PAS reaction was weakly positive, which suggested that the eosinophils contained large amounts of glycogen and occasionally traces of other polysaccharides. The presence of poly- 


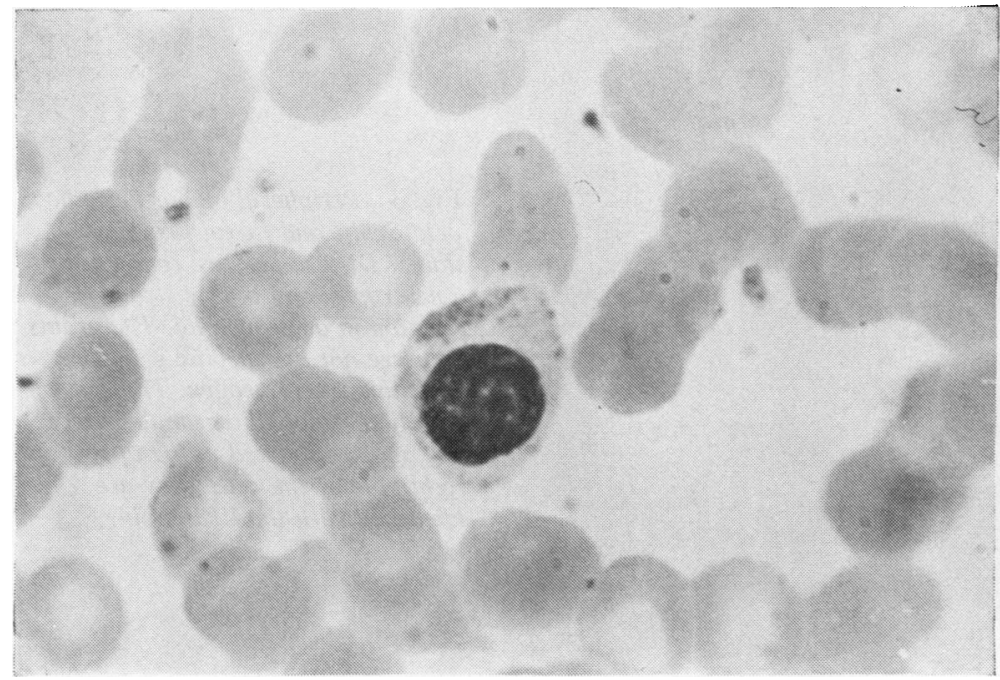

Fig. 1 Peripheral blood eosinophil shows a disproportion between the rate of maturation of the nucleus and cytoplasm. Also evident is a decrease in the number of specific granules and variation in their size.

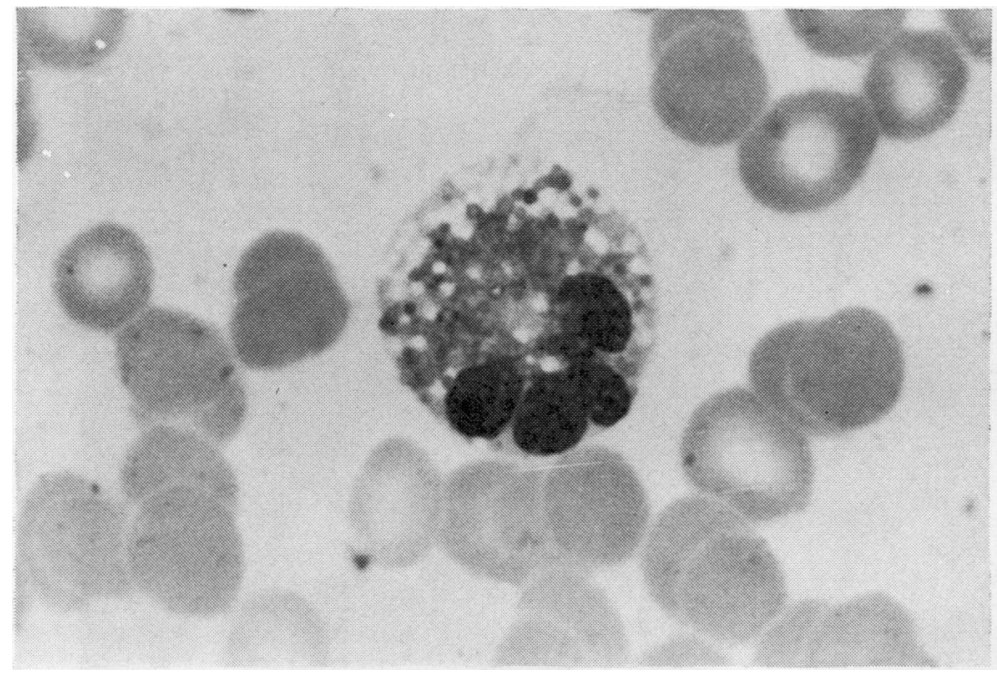

Fig. 2 A peripheral blood eosinophil with hypersegmentation of the nucleus and marked cytoplasmic vacuolisation.

saccharides in the cytoplasm was also detected by a combination of the PAS and LFB reactions, and by the triple staining (Presentey and Perk, 1972).

With the method of Graham and Knoll, positive peroxidase reaction was found in the granules of both eosinophils and neutrophils. However, when the Undritz modification was used, a positive peroxidase reaction was observed only in the specific granules of the eosinophils (Fig. 4). It should be mentioned that a few of the azurophilic- basophilic granules encountered in eosinophils did not show peroxidase activity. Azurophilic-basophilic granules were also detectable by the May GrünwaldGiemsa stain. In eosinophilic blast cells a positive peroxidase reaction was found both in the granules and in the intergranular cytoplasm.

No alkaline phosphatase activity was detected in the eosinophils, whereas that in the neutrophils was normal. High activity of acid phosphatase (Fig. 5) was found in the granules of the eosinophils, but 


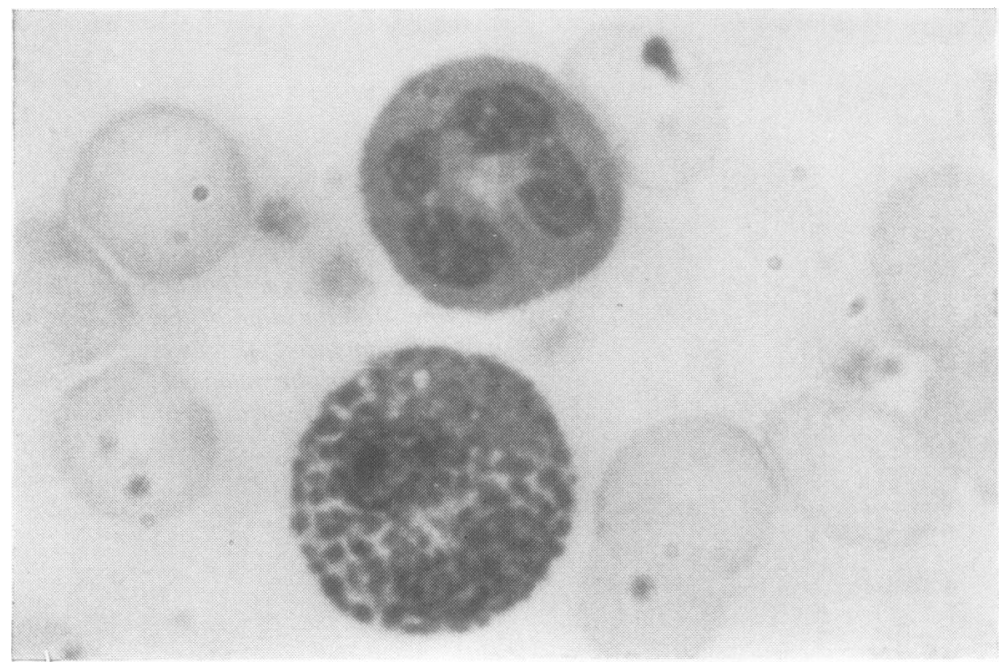

Fig. 3 Peripheral blood. Periodic acid Schiff and Luxol fast blue stains. Diffuse positive reaction in a neutrophil and a very strong reaction in an eosinophil. The grains seen are not the specific granules but clumps of glycogen. The specific eosinophilic granules are few and are located in the upper right pole of the cell. They are identified with the LFB stain.

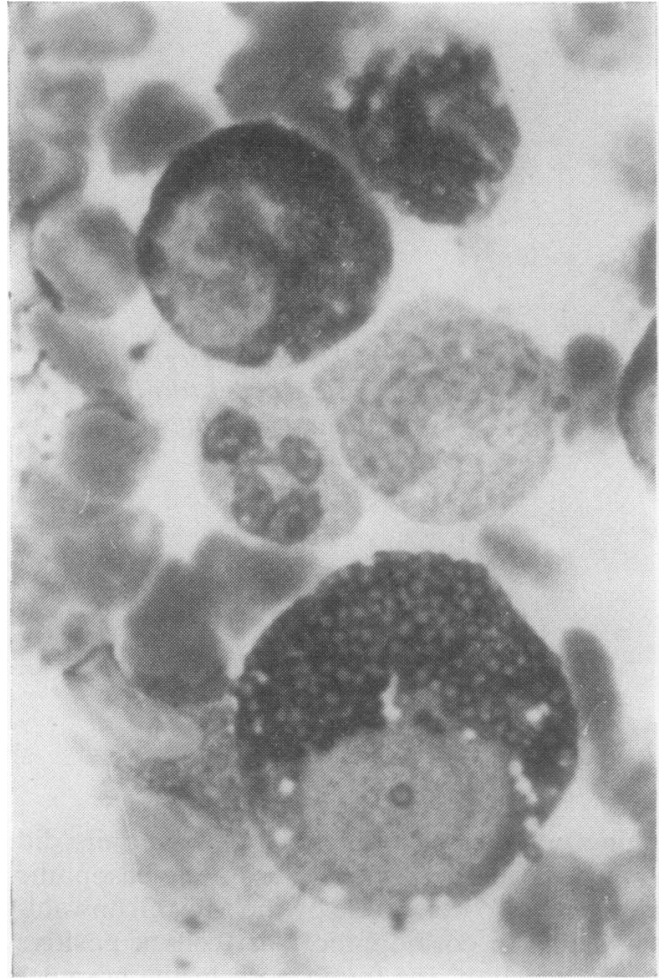

Fig. 4

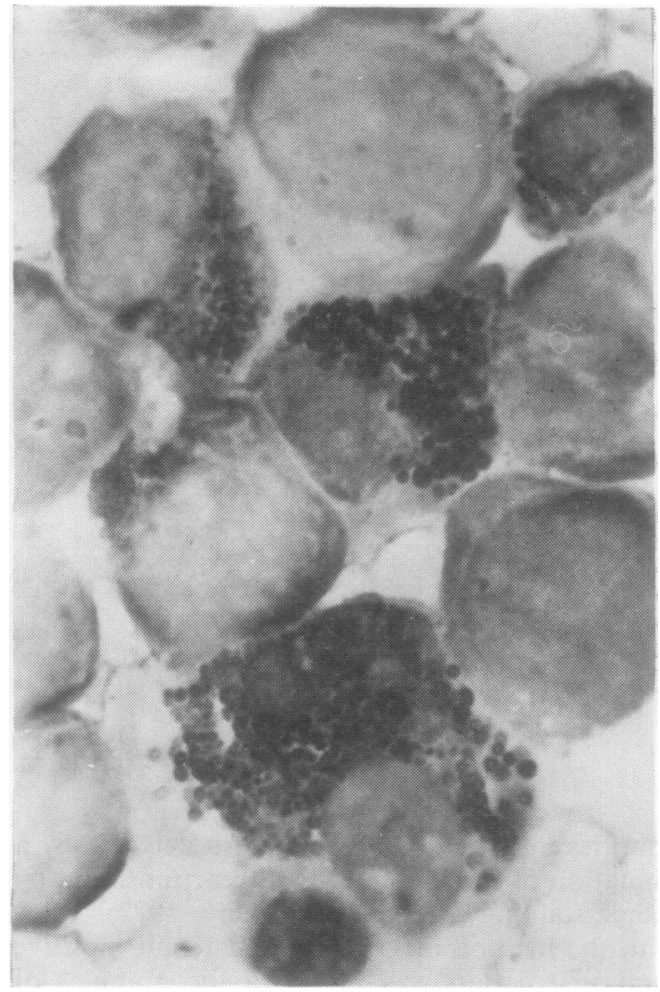

Fig. 5

Fig. 4 A selective peroxidase staining of bone marrow eosinophils according to Undritz shows significant differences between the specific granules. The eosinophilic myelocyte contains a considerable number of vacuoles.

Fig. 5 Bone marrow. Acid phosphatase reaction according to Gomori. A very strong positive reaction of the enzyme is seen in the eosinophils. 


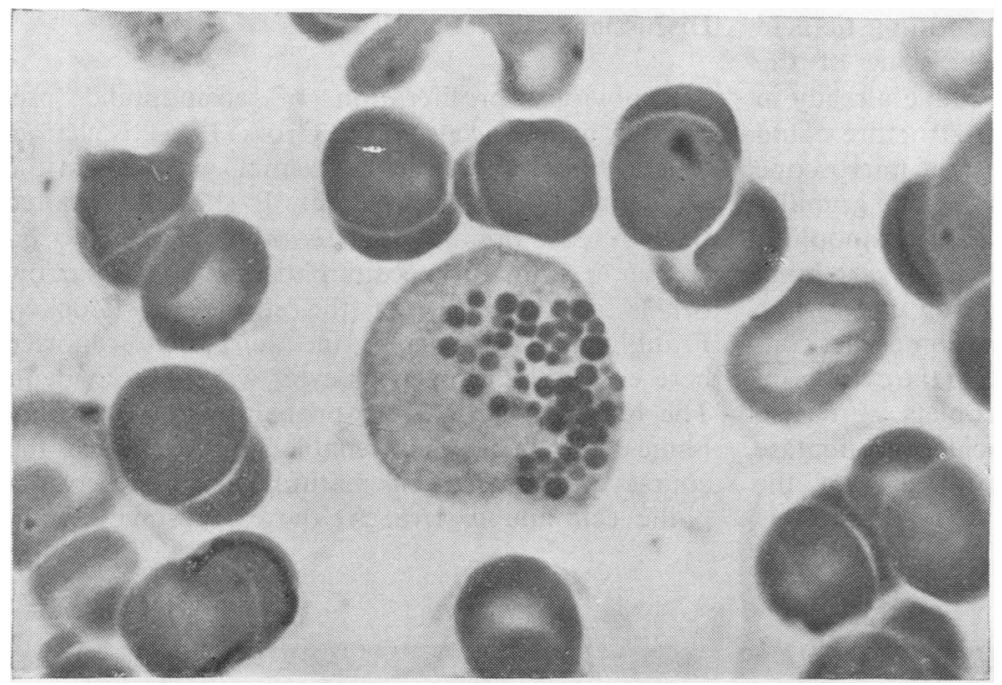

Fig. 6 Peripheral blood eosinophil showing a positive aryl sulphatase reaction.

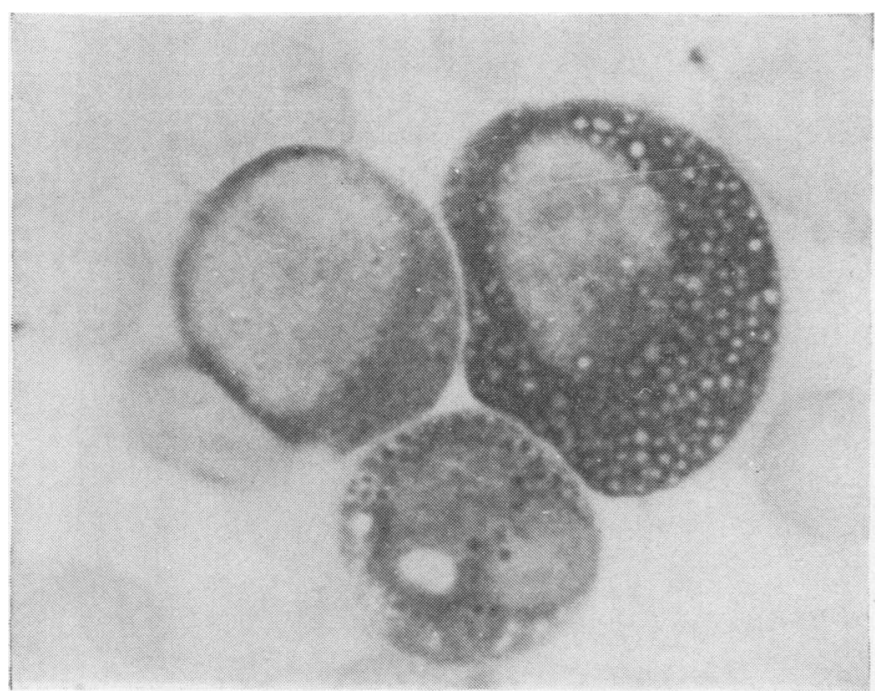

Fig. 7 Bone marrow. A positive reaction to ubiquinone is seen in all nucleated cells.

the non-specific esterases showed no activity. The activity of aryl sulphatase (Fig. 6) and of ubiquinone (Fig. 7) was found to be normal.

\section{ELECTRON MICROSCOPY}

In sections fixed with glutaraldehyde and osmium tetroxide, the nuclei of young eosinophilic cells contained a small amount of heterochromatin, most of it concentrated near the nuclear wall. The extent and location of peroxidase activity in the cells enabled us to trace the maturation process of eosinophilic cells. In the blast stage peroxidase activity was found in the Golgi apparatus and in the endoplasmic reticulum, including that surrounding the nucleus (Fig. 8), but not in the mitochrondria. In the more mature cells, which have less endoplasmic reticulum, the peroxidase activity of the circum-nuclear endoplasmic reticulum was weak or absent (Figs 9-11), but the typical granules gave a positive peroxidase reaction. Staining with potassium 
pyroantimonate (Fig. 12) and phosphotungstic acid was positive throughout. The inner zone of the granules - the cristalloid - was detectable already in the promyelocytes, but the lamellar structure could not be seen at this stage. As in the light microscope study, a decrease in the number of specific granules was observed in some of the mature eosinophils. In such cells the granules showed great variability in size, and some of them were already undergoing destruction (Fig. 13). Much glycogen, sometimes concentrated in large masses, was found in the cytoplasm of mature eosinophils, and fat droplets were also evident (Fig. 14). Eventually acid phosphatase activity was detected in the protoplasm of the cells.

\section{Discussion}

An obvious proliferation of eosinophilic precursors, which, according to Gross (1962), is characteristic for eosinophilic leukaemia, was seen in the bone marrow of our patient. It should be noted that in eosinophilia due to other causes the increase in immature eosinophils in bone marrow begins at the stage of the myelocyte (ZuckerFranklin, 1974) whereas in the patient reported here eosinophilic promyelocytes were also evident. The blasts, as well, were probably of the eosinophilic cell line. This enabled us to trace the course and process of maturation of the eosinophilic cell line in vivo. At the early stage of im-

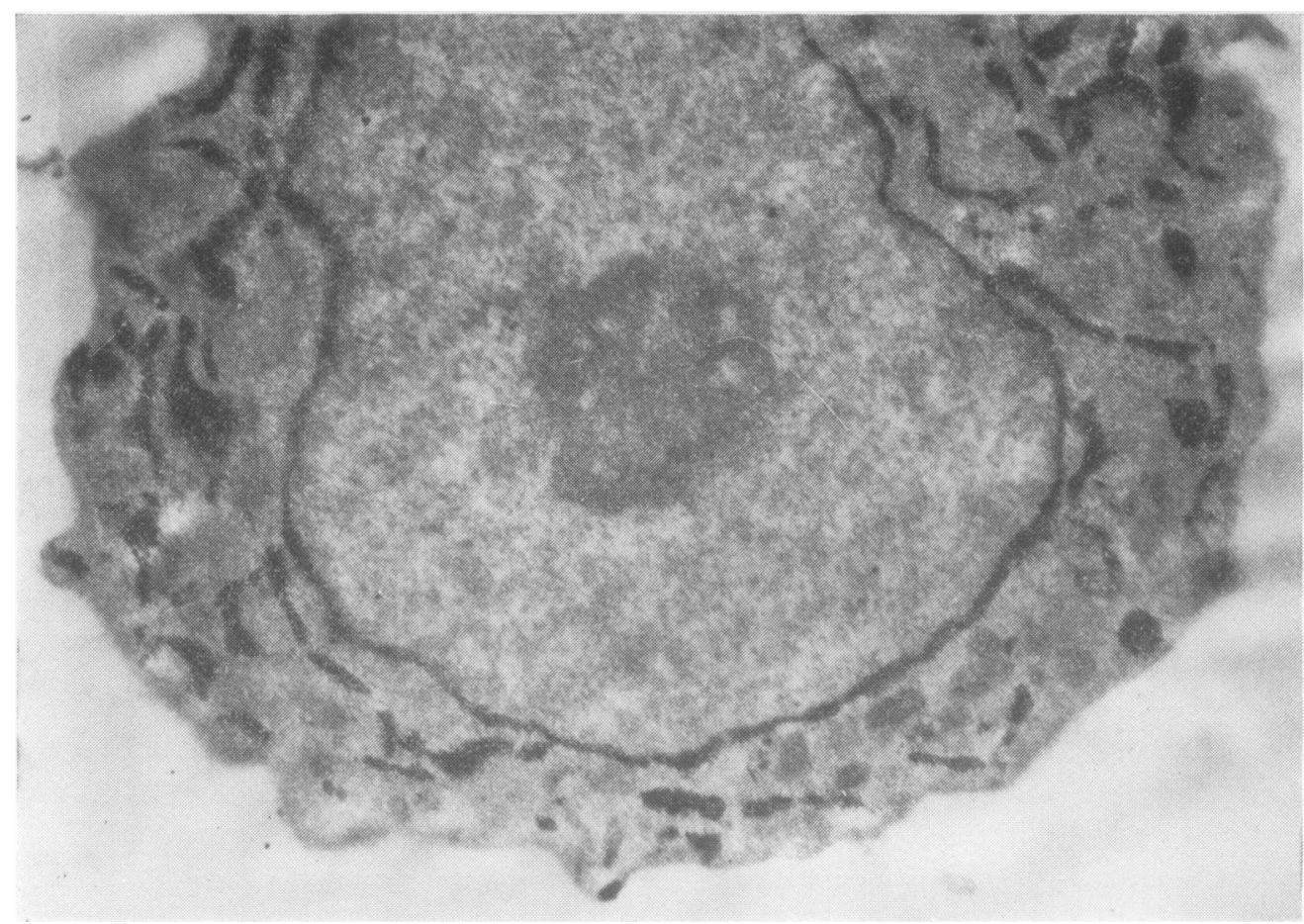

Fig. 8

Figs. 8-11 Peroxidase reaction. Eosinophils in different stages of maturation. There are no identifying characteristics as yet in the blast cell. A strong positive reaction is seen in the endoplasmic reticulum, and in the nuclear envelope (Fig. 8). With cell maturation, the positive stain of the endoplasmic reticulum and the nucleus envelope gradually dimirishes (Fig. 9). The nucleus of the blast cell and of the early promyelocyte contains a large nucleus (Figs 8 and 9). The nuclear heterochromatin appears in later stages. Golgi apparatus shows a positive reaction (Fig. 10). The specific granules appear only in the promyelocyte stage, their number increasing with cell maturation. The crystalloid (Fig. 11) is identifiable in the late stages of cell maturation. (Fig. 8-3 3 7000; Figs 9 and 10-3 $35000 ;$ Fig. 11-2 $\times 2000$ ). Unstained. 


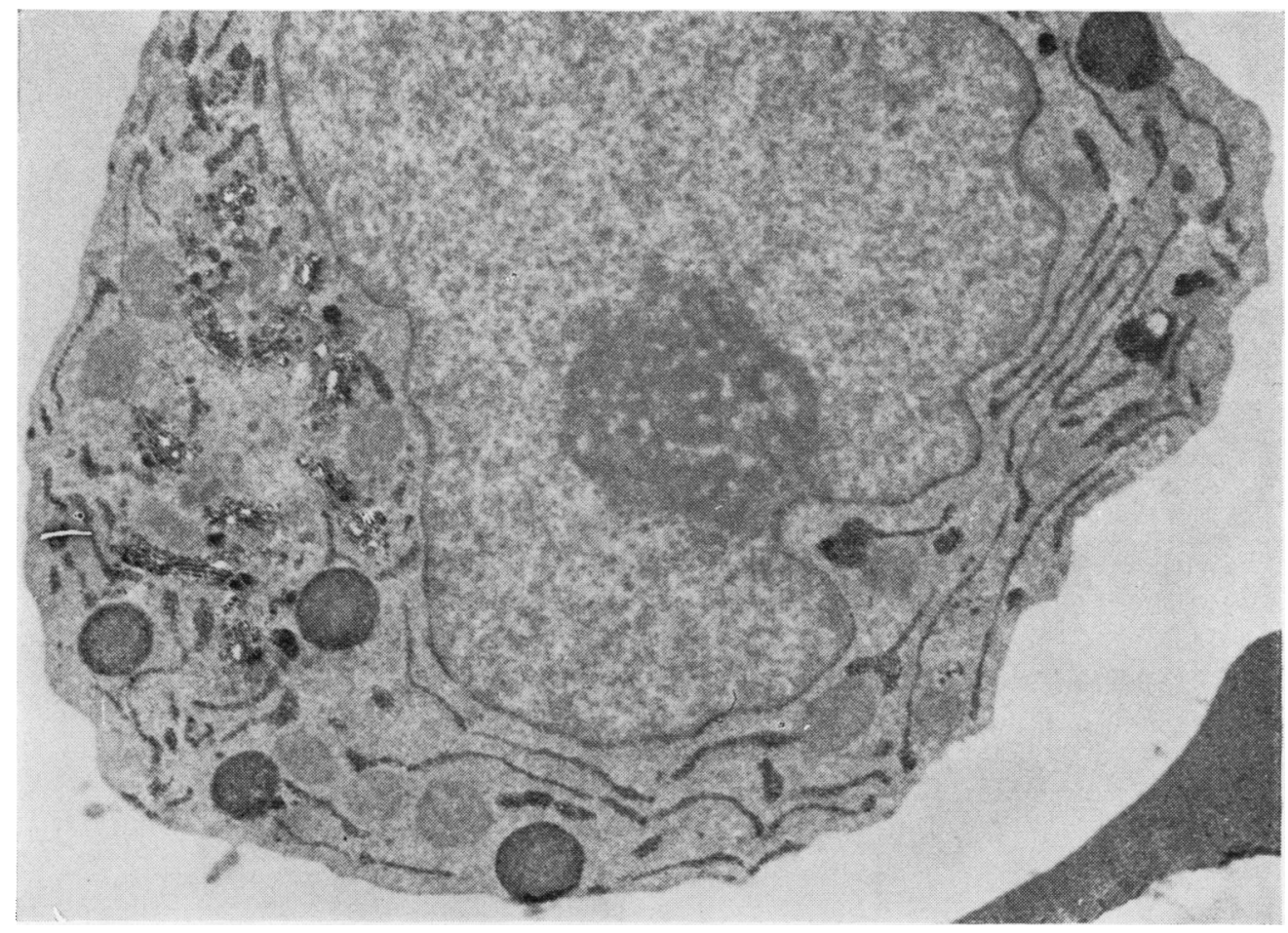

Fig. 9

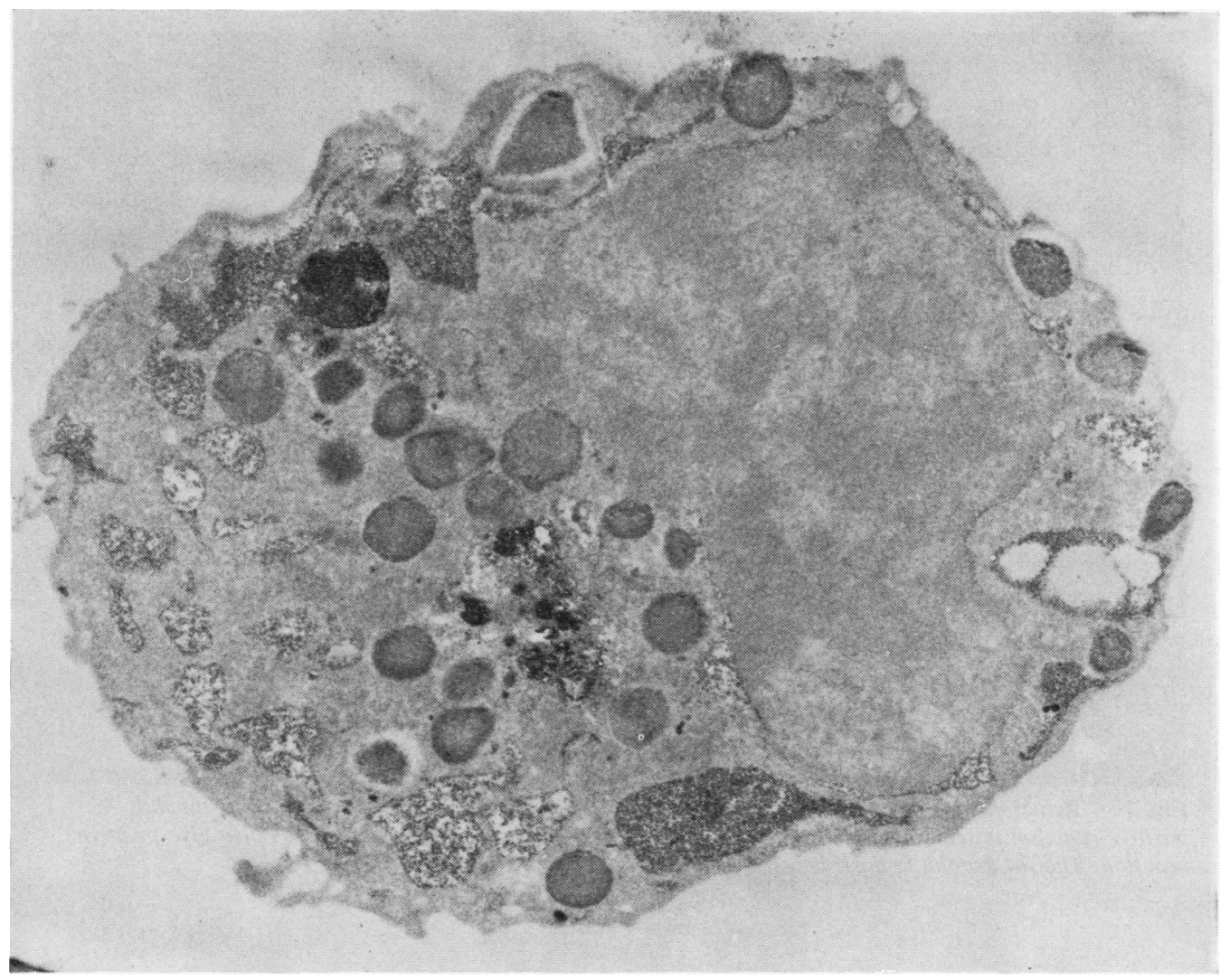

Fig. 10 


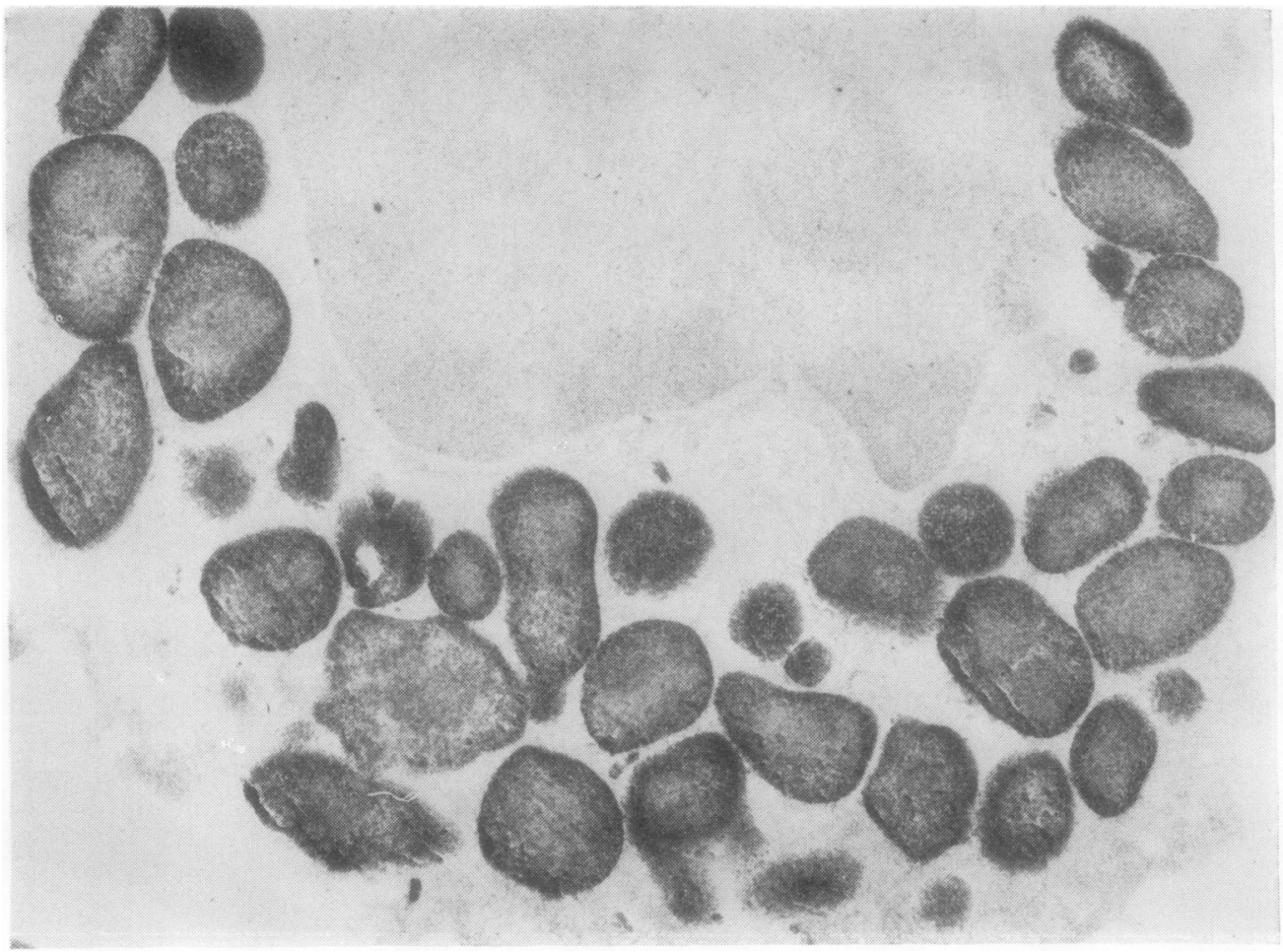

Fig. 11

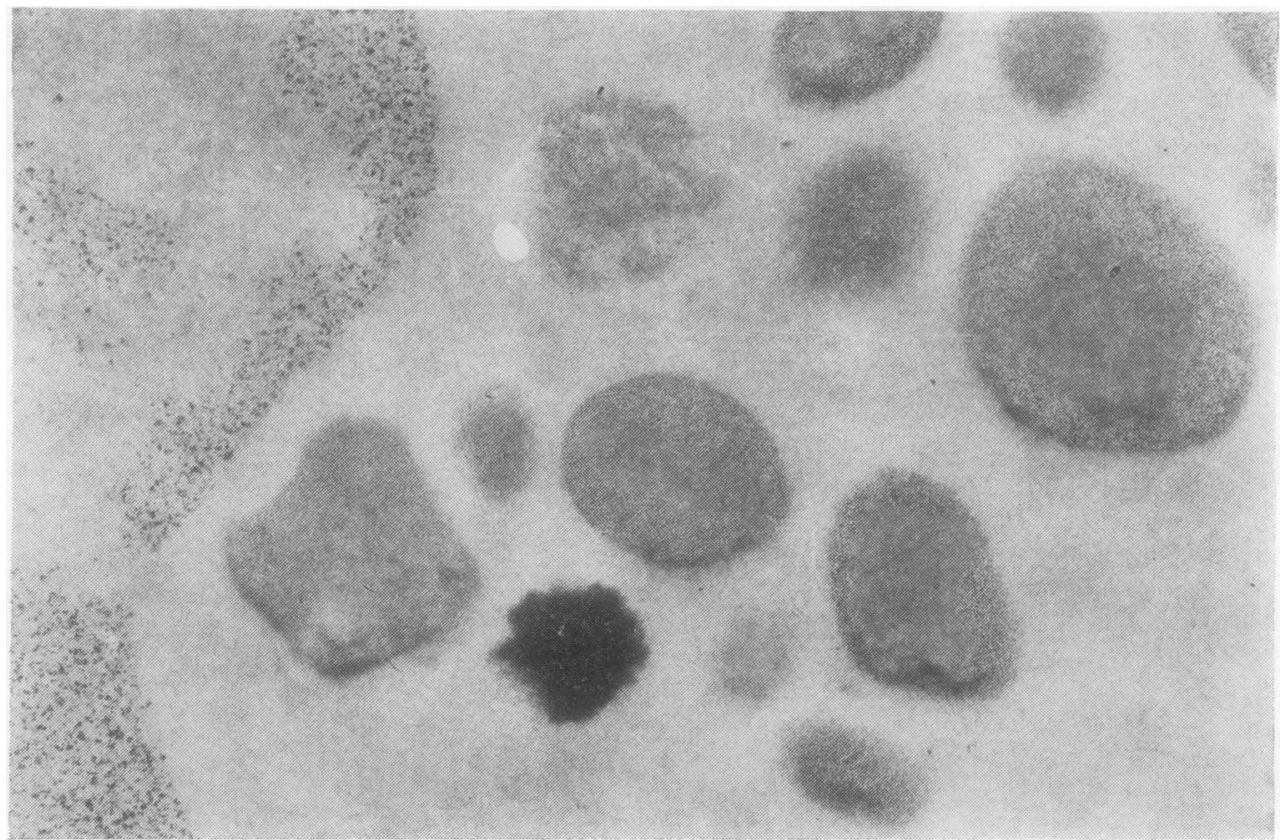

Fig. 12 Reaction with potassium pyroantimonate. Part of a mature peripheral blood eosinophil. A positive reaction is seen in the outer layer of the mature granules. Primary granules also give positive reaction. The fat droplet is dark because of the $\mathrm{OsO}_{4}(3 \times 17000)$. Unstained. 
mature cells, abundant peroxidase activity was detected in the cellular and perinuclear endoplasmic reticulum. However, as the cells matured, the peroxidase activity and the amount of their endoplasmic reticulum decreased, and concurrently a different typical peroxidase reaction of the eosinophilic granules appeared. In the very young cells it was impossible to differentiate between the two zones of the specific granules because peroxidase activity occurred throughout the granule. In later stages, however, the two zones of the granule, the inner composed of basic protein and the other containing peroxidase, could easily be distinguished. Our description of the eosinophilic maturation process, based on the peroxidase activity, is similar to that by Hardin and Spicer (1970), who used pyroantimonate, and by Hudson (1966b), who used phosphotungstic acid in their studies. We did not observe synchronisation between maturation of the nucleus and that of the cytoplasm, as was previously described by Weinger et al. (1975).

Our finding of abnormally high glycogen content in the cells is in agreement with similar findings by Gross (1962), Weinger et al. (1975), Wulfhekel et al. (1975), Ackerman (1964), and Schaefer et al. (1973). According to Ackerman (1964), the high content of glycogen might be due to hyperactivity of phosphorylase, but there is as yet no evidence in support of this suggestion, and other explanations are equally valid; for instance, the high glycogen content could stem from an increased activity of glycogen synthetase or, alternatively, from a decrease or inhibition of glycogen phosphorylase, which degrades glycogen.

The specific eosinophilic granules were observed by us to be highly variable in size. A similar observation has been made by others (Schaefer et al., 1973; Zucker-Franklin, 1974; Weinger et al., 1975). Azurophilic-basophilic granules, as described by Gross (1962), were also observed, and although they may appear in normal eosinophils as well, their number in such cases is very small and they occur only in eosinophils of bone marrow and not in those of peripheral blood. Some osmophilic granules

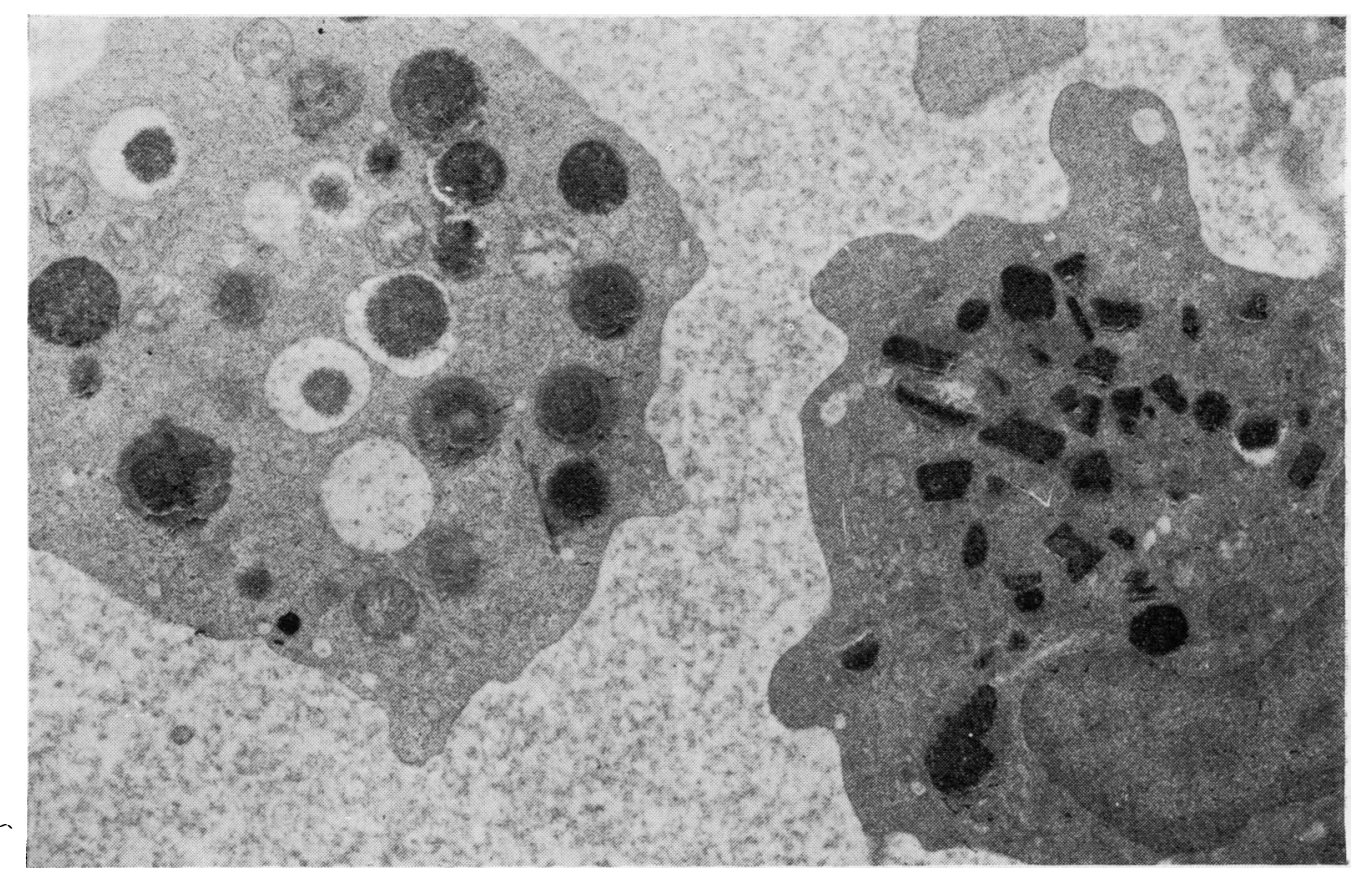

Fig. 13

Figs. 13-14 Peripheral blood eosinophils. Double stain with urany acetate and lead citrate. In the majority of the cells the presence of glycogen is noted (Fig. 14). The scarcity of granules is primary. A process of degranulation, starting in the external part of the granules and later affecting also the crystalloid, is evident. Note also the variability in size of the specific granules (Fig. 13). (Fig. 13-3 4000; Fig. 14-3 × 3500). 


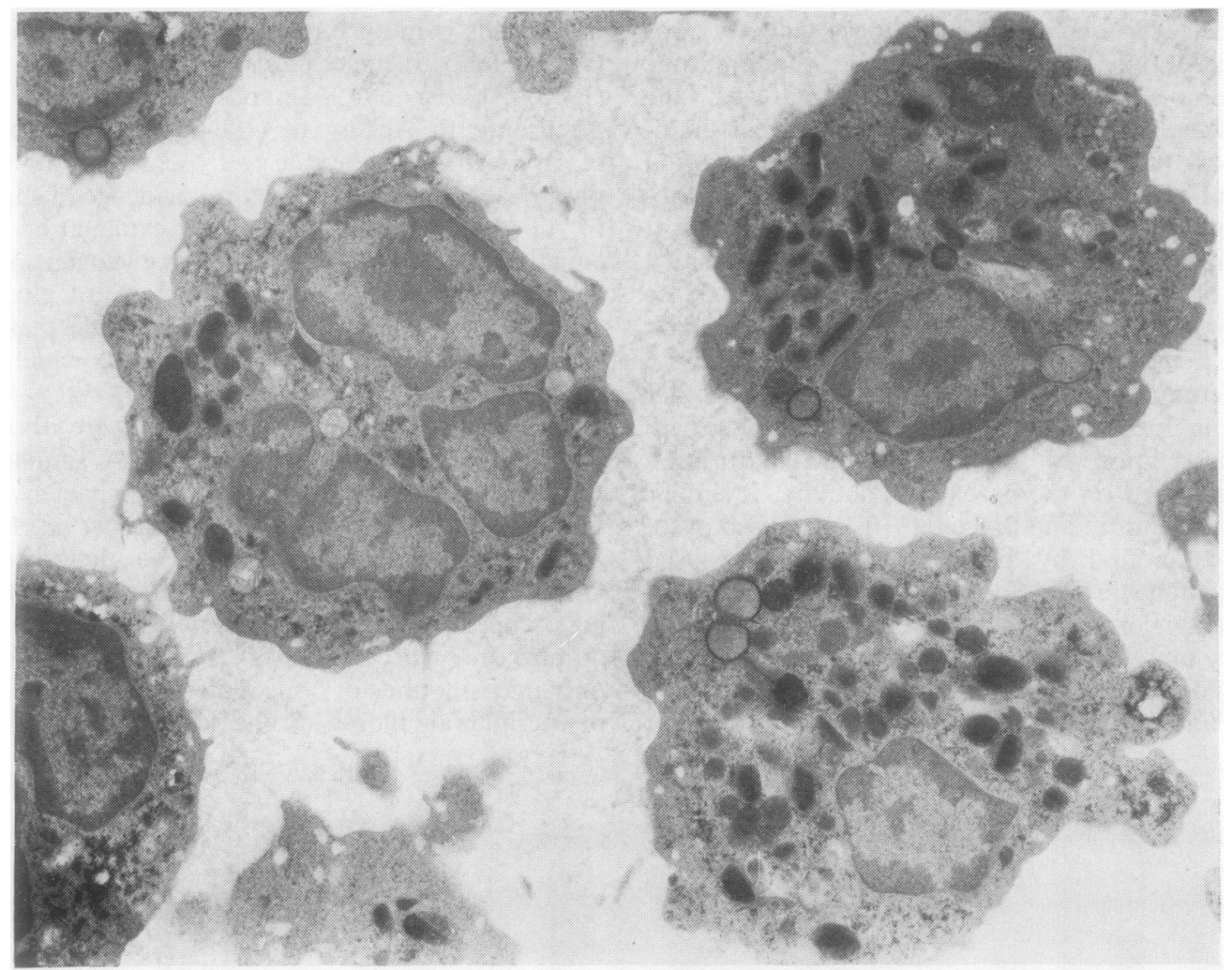

Fig. 14

were detected in our electron microscopic preparations. These were considered by ZuckerFranklin (1971) to be progranules, but we do not concur with this opinion because we could not detect in the granules any peroxidase or other characteristic enzyme activity.

All our findings confirm the diagnosis of eosinophilic leukaemia in this patient. It is our opinion that eosinophilic leukaemia as such is not merely a type of chronic myelogenous leukaemia, as suggested by Benvenisti and Ultmann (1969) and Wulfhekel et al. (1975), but rather a separate, discrete disease entity. The present case offers further evidence that the eosinophils form a distinct cell line in the bone marrow. Such a conclusion was previously made by us concerning eosinophils which are devoid of phospholipids and peroxidase (Presentey, 1969, 1970). A similar suggestion has also been made by Honsinger et al. (1972), Undritz (1973), and Zucker-Franklin (1974).

This work is part of the PhD thesis submitted by one of us (BP) to the Tel-Aviv University.

\section{References}

Ackerman, G. A. (1964). Eosinophilic leukemia. A morphologic and histochemical study. Blood, 24, 372-388.

Ackerman, G. A., and Clark, M. A. (1971). Ultrastructural localization of peroxidase activity in normal human bone marrow cells. Zeitschrift für Zellforschung und mikroskopische Anatomie, 117, 463-475.

Bengtsson, E. (1968). Eosinophilic leukemia -an immunopathological reaction? Acta Paediatrica Scandinavica, 57, 245-249.

Bently, H. P., Jr., Reardon, A. E., and Knoedler, J. P. (1961). Eosinophilic leukemia. American Journal of Medicine, 30, 310-322.

Renvenisti, D. S., and Ultmann, J. E. (1969). Eosinophilic leukemia. Report of five cases and review of literature. Annals of Internal Medicine, 71, 731-745.

Chusid, M. J., Dale, D. C., West, B. C., and Wolff, S. M. (1975). The hypereosinophilic syndrome: analysis of fourteen cases with review of the literature. Medicine (Baltimore), 54, 1-27.

Dvilansky, A., Alkan, M. L., Ho, W., Kaplan, J., Tiberin, P., and Rachmilewitz, B. (1975). Chronic eosinophilic leukemia complicated by epidural myeloblastoma. Acta Haematologica, 53, 356-361. 
Flannery, E. P., Dillon, D. E., Freeman, M. V. R., Levy, J. D., d'Ambrosio, U., and Bedynek, J. L. (1972). Eosinophilic leukemia with fibrosing endocarditis and short $\mathrm{Y}$ chromosome. Annals of Internal Medicine, 77, 223-228.

Goldfischer, S. (1965). The cytochemical demonstration of lysosomal aryl sulfatase activity by light and electron microscopy. Journal of Histochemistry and Cytochemistry, 13, 520-523.

Goldstein, D. J. (1963). Selective staining of eosinophil granules in sections by alkaline orcein in a concentrated urea solution. Stain Technology, 38, 49-51.

Gomori, G. (1952). Microscopic Histochemistry, p. 207. University of Chicago Press, Chicago, Illinois.

Gomori, G. (1968). The lead nitrate method for acid phosphatase. In Histochemistry, Theoretical and Applied, edited by A. G. E. Pearse, 3rd edition, Volume I, p. 728. Churchill, London.

Graham, G. S., and Knoll, W. (1973). Peroxidase reaction for general differentiation. In Sandoz Atlas of Haematology, edited by E. Undritz, 2nd edition. Sandoz, Basle.

Gross, R. (1962). The eosinophils. In The Physiology and Pathology of Leukocytes, edited by $\mathrm{H}$. Braunsteiner, American edition revised by D. Zucker-Franklin, pp. 1-45. Grune and Stratton, New York and London.

Hardin, J. H., and Spicer, S. S. (1970). An ultrastructural study of human eosinophil granules: maturational stages and pyroantimonate reactive cation. American Journal of Anatomy, 128, 283-297.

Hardy, W. R., and Anderson, R. E. (1968). The hypereosinophilic syndromes. Annals of Internal Medicine, 68, 1220-1229.

Honsinger, R. W., Jr., Silverstein, D., and Van Arsdel, P. P., Jr. (1972). The eosinophil and allergy: why? Journal of Allergy and Clinical Immunology, 49, 142-155.

Hotchkiss, R. D. (1948). A microchemical reaction resulting in the staining of polysaccharide structures in fixed tissue preparations. Archives of Biochemistry, 16, 131-141.

Hudson, G. (1966a). Eosinophil granules and phosphotungstic acid: an electron microscope study of guineapig bone marrow. Experimental Cell Research, 41, 265-273.

Hudson, G. (1966b). Eosinophil granules and cell maturity: electron microscopic observations on guinea-pig marrow. Acta Haematologica, 36, 350-360.

Kaplow, L. S. (1955). A histochemical procedure for localizing and evaluating leukocyte alkaline phosphatase activity in smears of blood and marrow. Blood, 10, 1023-1029.

Karle, J., and Videbaek, A. (1966). Eosinophilic leukemia or a collagen disease with eosinophilia. Danish Medical Bulletin, 13, 41-45.

Lison, E. (1973). Fat staining with Sudan black B according to Lison. In Sandoz Atlas of Haematology, edited by E. Undritz, 2nd edition, p. 38. Sandoz, Basle.

Moloney, W., McPherson, K., and Fliegelman, L. (1960). Esterase activity in leukocytes demonstrated by the use of naphthol AS-D chloroacetate substrate. Journal of Histochemistry and Cytochemistry, 8, 200-207.
Odeberg, B. (1965). Eosinophilic leukemia and disseminated eosinophilic collagen disease-a disease entity? Acta Medica Scandinavica, 177, 129-144.

Presentey, B. (1969). Cytochemical characterization of eosinophils with respect to a newly discovered anomaly. American Journal of Clinical Pathology, 51, 451-457.

Presentey, B. (1970). Partial and severe peroxidase and phospholipid deficiency in eosinophils. Acta Haematologica, 44, 345-354.

Presentey, B., and Perk, K. (1972). Simultaneous staining of phospholipids, basic proteins and glycogen on the same slide. Journal of Clinical Pathology, 25, 608-610.

Schaefer, H. E., Hellriegel, K. P., Hennekeuser, H., Hübner, G., Zach, J., Fischer, R., and Gross, R. (1973). Eosinophilenleukämie, eine unreifzellige Myelose mit Chloroacetatesterase-positiver Eosinophilie. Blut, 26, 7-19.

Seeman, P. M., and Palade, G. E. (1967). Acid phosphatase localization in rabbit eosinophils. Journal of Cell Biology, 34, 745-756.

Sheehan, H. L. (1939). The staining of leukocyte granules by Sudan black B. Journal of Pathology and Bacteriology, 49, 580-581.

Spitzer, G., and Garson, O. M. (1973). Lymphoblastic leukemia with marked eosinophilia: a report of two cases. Blood, 42, 377-384.

Tallgren, L. G., Wegelius, R., Andersson, L. C., and Jansson, E. (1974). Eosinophilic leukemia: recovery of mycoplasma orale from the bone marrow. Acta Medica Scandinavica, 195, 87-92.

Tranzer, J. P., and Pearse, A. G. E. (1963). Cytochemical demonstration of ubiquinones in animal tissues. Nature, 199, 1063-1066.

Undritz, E. (1973). Peroxidase reaction, modification II for eosinophils according to Undritz. In Sandoz Atlas of Haematology, edited by E. Undritz, 2nd edition, p. 33. Sandoz, Basle.

Watanabe, I. Donahue, S., and Hoggatt, N. (1967). Method for electron microscopic studies of circulating human leukocytes and observations on their fine structure. Journal of Ultrastructure Research, 20, 366-382.

Weinger, R. S., André-Schwartz, J., Desforges, J. F., and Baker, M. (1975). Acute leukaemia with eosinophilia or acute eosinophilic leukaemia: a dilemma. British Journal of Haematology, 30, 65-70.

Wulfhekel, U., Düllmann, J., Bartels, H., and Hausmann, K. (1975). Zur Ultrastruktur und Cytochemie von eosinophil-myelomonocytären Leukämien. Virchows Archiv A, Pathological Anatomy and Histology, 365, 289-308.

Yuill, G. M., Lascelles, R. G., and Scholtz, C. (1974). Eosinophilic leukaemia terminating with an encephalopathy. Postgraduate Medical Journal, 50, 473-478.

Zucker-Franklin, D. (1971). Eosinophilia of unknown etiology: a diagnostic dilemma. Hospital Practice, 6, 119-127.

Zucker-Franklin, D. (1974). Eosinophil function and disorders. Advances in Internal Medicine, 19, 1-25.

Requests for reprints to: Dr B. Presentey, Department of Hematology, Kupath Holim, District Laboratory, Rehovoth, Israel. 